\title{
Kinetics of plasma lysine after oral and parenteral administration to pigs
}

J. M. FENTENER VAN VLISSINGEN 4 , J. G. M. BAKKER ${ }^{1}$, L. P. JAGER ${ }^{2}$, N. P. LENIS 1 , H. DE VISSER ${ }^{1}$, F. G. M. RUSSEL ${ }^{3} \&$ J. E. VAN DIJK ${ }^{2}$

1 Research Institute for Livestock Feeding and Nutrition, P.O. Box 160, NL 8200 AD Lelystad, Netherlands

2 Central Veterinary Institute, Lelystad, Netherlands

3 Department of Pharmacology, Faculty of Medicine and Dentistry, University of Nijmegen, Netherlands

4 Present address: TNO Institute of Animal Nutrition and Physiology, P.O. Box 15, NL 6700 AA Wageningen, Netherlands

Received 28 February 1990; accepted 8 May 1990

\begin{abstract}
The classical method to evaluate bioavailability of dietary amino acids by the assessment of digestibility (disappearance from digesta) is subject to some intrinsic sources of error. The levels of circulating amino acids might provide a more accurate estimate of the pool of substrates available for protein synthesis by non-visceral compartments of the body. The fate of lysine, administered to growing pigs ( $\pm 45 \mathrm{~kg}$ live weight) via oral or parenteral routes, was quantified by pharmacokinetic analysis of systemic plasma concentrations. Slow portal or systemic intravenous infusion was performed to mimick enteral uptake and rapid infusion provided data on the initial distribution volume and biological half-life. Elimination rate after intravenous administration had a half-life of $2.0 \pm 1.6 \mathrm{~h}$ (after bolus injection) or 3.7 $\pm 1.9 \mathrm{~h}$ (after slow infusion). Absorption of an oral dose of lysine from the intestine (half-life of $3.6 \pm 0.9 \mathrm{~h}$ ) was slower than elimination rate (half-life of $0.9 \pm 0.3 \mathrm{~h}$ ). No significant liver first-pass effects could be detected and bioavailability of lysine after enteral uptake was found to be $82 \pm 6 \%$. Analysis of plasma kinetics of amino acids may provide a valuable tool to evaluate bioavailability of dietary amino acids.
\end{abstract}

Keywords: pigs, amino acids, plasma, pharmacokinetics

\section{Introduction}

The growth of animal tissues depends on the availability of substrates and a complex of growth regulatory mechanisms (Buttery \& Lindsay, 1980). Animal nutrition research typically studies the supply of substrates by feed. The maximum attainable bioavailability of substrates for tissue growth is reflected by the digestibility of 
nutrients from feed, as measured by the disappearance from digesta (Rerat, 1985; Sauer \& Ozimek, 1986). The bioavailability depends also on the metabolic economy of intestinal microflora and the uptake and transport processes in the tissues composing the wall of the gastrointestinal tract. The post-intestinal bioavailability of nutrients provides a more accurate estimate of potential utilization, by nonintestinal tissues, than their disappearance from digesta. Hepatic metabolism of substances absorbed by the intestine may influence the bioavailability of nutrients for growth of other tissues (Rerat, 1985; Jahoor et al., 1988; van Berlo, 1988).

The concentration of substrates in the systemic blood is determined by:

1. increase kinetics, dependent on gastrointestinal and liver processing of nutrients (Rerat, 1985);

2. degradation products from tissue catabolism (Edmonds et al., 1987; Kimura et al., 1987);

3. elimination kinetics, determined by metabolism in many different tissues (biosynthesis, oxidation) and excretion of the substrate or its metabolites (Condon, 1986; Tsuchiya et al., 1989).

Although the mechanisms which influence the kinetics of blood concentrations are extremely complex, the blood concentrations, as measured directly, are relevant for the availability of nutrients at the tissue level. Pharmacokinetic analysis provides parameters on uptake rate, total bioavailability, reduction rate, and putative firstpass effects. Quantitative parameters may be instrumental to indicate, though not identify, different metabolic routes.

The present experiment was designed to determine the kinetics of plasma lysine after oral, portal and systemic administration. The applicability of a pharmacokinetic approach to the evaluation of bioavailability of nutrients is discussed.

\section{Materials and methods}

\section{Animals}

Three pigs (cross-breed of Dutch Landrace $\times$ Large White), aged 14 to 15 weeks, were housed individually in pens and fasted overnight prior to surgery. General anesthesia was induced and maintained by inhalation of $\mathrm{O}_{2} / \mathrm{N}_{2} \mathrm{O}$ and Halothane (Trofield). After induction of anesthesia, tracheal intubation was performed and respiration was maintained mechanically (positive end-expiratory pressure).

Catheter positioning is shown schematically in Figure 1. Laparotomy was performed by a vertical incision in the right flank, that extended from the epaxial lumbar musculature to the ventralmost portion of the cutaneous trunci muscle. The caudal mesenteric vein was exposed by blunt dissection of the descending mesocolon. A Tygon catheter (inner diameter $1.0 \mathrm{~mm}$ and outer diameter $1.8 \mathrm{~mm}$, from Talas), prepared with an external fixation ring, was trimmed to have a blunt end and filled with physiological saline $(0.15 \mathrm{M} \mathrm{NaCl})$ containing 250 IU Na-Heparin (Leo) $\mathrm{ml}^{-1}$. After fixation of the vein by loose reins of nylon suture material, venotomy was performed, followed by introduction of the catheter tip, while flushing the catheter. The catheter was advanced cranially over a distance of approximately 12 


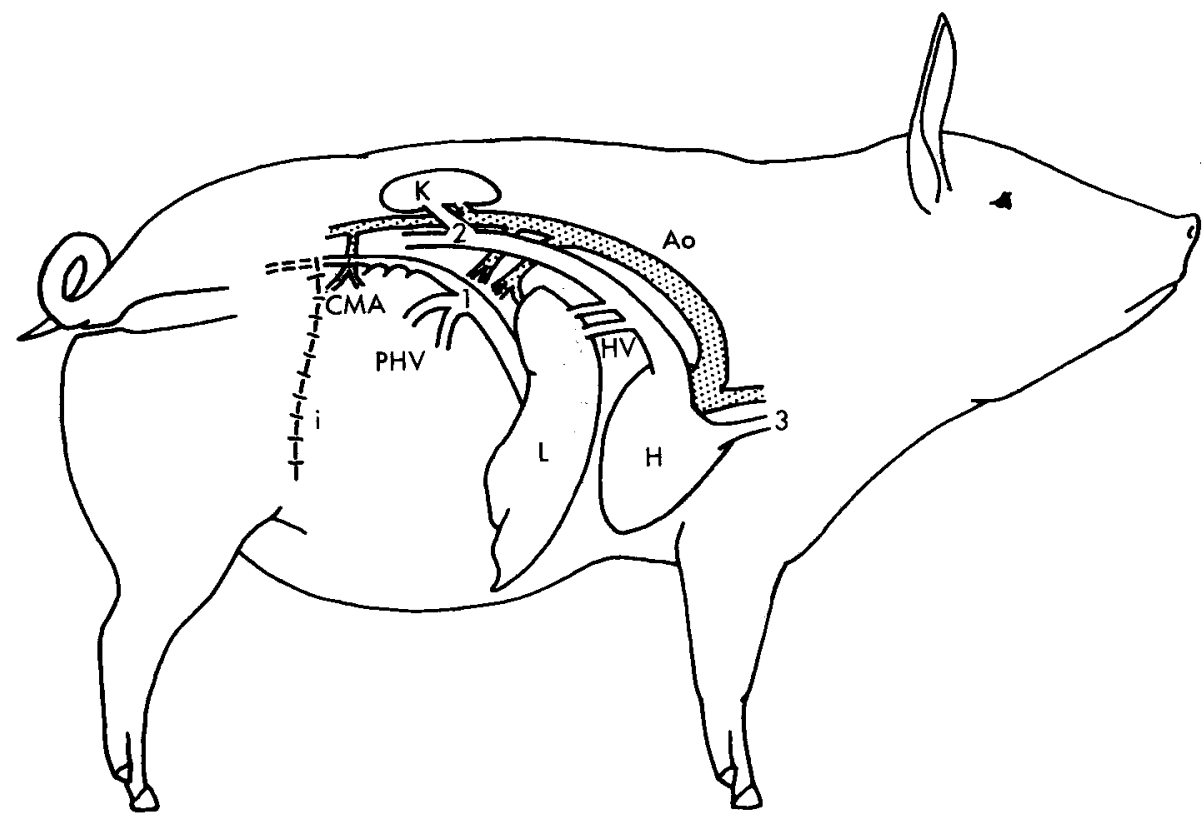

Fig. 1. Schematic drawing of position of portal, caval and jugular catheters and surgical access to the abdominal cavity. Shaded vessels are arteries and open vessels are veins (portal or systemic). Abbreviations: $\mathrm{Ao}=$ aorta; $\mathrm{CMA}=$ caudal mesenteric artery; $\mathrm{H}=$ heart; $\mathrm{HV}=$ hepatic veins, draining into the caudal caval vein; $\mathrm{i}=$ incision; $\mathbf{K}=$ kidney; $\mathrm{L}=$ liver; $\mathbf{P H V}=$ portal hepatic vein. Location of tip of catheters: $1=$ portal; $2=$ caval; $3=$ jugular.

$\mathrm{cm}$, corresponding to a position of the tip near the junction of the caudal and cranial mesenteric veins. The caudal mesenteric vein was then ligated over the catheter cranial to the venotomy site and the vein was completely occluded by ligation caudal to this site (polyamide, Serafil, Serag-Wiessner). The blood from the caudal portion of the vein drained to the rectal veins via pre-existent anastomoses without any apparent obstructions. The intra-abdominal portion of the catheter was secured within a fold of peritoneum that was sutured in place. Additional sutures were used to fix the fixation ring of the catheter. The catheter was guided through the peritoneum, the flank musculature and the subcutis of the back, and exteriorized beyond the midsagittal plane of the body. Closure of the laparotomy was done using Vicryl 2-0 (Ethicon $\mathrm{GmbH}$ ) with an interrupted suturing pattern for each muscle layer and the skin. In one out of three animals, the sham-operated control, the catheter was introduced into a lumbar branch of the caudal caval vein, within the same region of the abdomen.

After completion of the abdominal surgery the position of the animal was changed from left lateral to dorsal recumbancy and the ventral aspect of the neck was prepared for sterile surgery. The left deep jugular vein was exposed by a paramedian incision followed by blunt dissection. Another Tygon catheter was re- 
pared as described before and introduced caudally after venotomy. The tip of the catheter was situated beyond the junction of veins draining head, neck and forelimbs. After ligating the jugular vein, the catheter was guided subcutaneously to be exteriorized at the right dorsal aspect of the neck. The catheter exteriorization sites were decontaminated with $70 \%\left(\mathrm{v} \mathrm{v}^{-1}\right)$ ethanol and covered with adhesive bandage. A jugular intravenous infusion of $300 \mathrm{ml}$ of isotonic saline was administered during recovery from anesthesia. The free length of the catheters was losely taped to the shoulder and back areas of the animal. No antibacterial or analgesic therapy was indicated.

The animal was allowed to recover from surgery for three days before the experiments were started. Experimental ration was offered each morning at 8:00 $\mathrm{h}$ and rectal temperature was measured daily throughout recovery and experimental periods, while the animal was eating.

Catheters were flushed daily with physiological saline containing 250 IU heparin $\mathrm{ml}^{-1}$. When not in use, the catheters were filled with the same solution and stoppered by the introduction of a sterile brass nail into the catheter lumen. The free length of catheter was losely taped to the dorsal aspect of the animal. For blood sampling or intravenous infusions a Luer lock hypodermic needle $(1.1 \mathrm{~mm})$ was introduced into the catheter. Slow intravenous infusions were administered through a disposable IV-infusion device (Intrafix Air, B. Braun). Rapid infusions were performed with $60 \mathrm{ml}$ syringes. For blood collection a syringe containing heparinized saline was connected to the catheter. After minute flushing the saline was withdrawn from the catheter and an empty heparinized syringe was connected for the collection of $4 \mathrm{ml}$ blood each time. The blood sample was then immediately transferred to a centrifuge tube cooled on ice. After centrifugation $\left(1600 \times \mathrm{g}, 10\right.$ minutes, $\left.4^{\circ} \mathrm{C}\right)$ the plasma was transferred to microvessels and frozen at $-20^{\circ} \mathrm{C}$ prior to deproteinization.

After completion of the series of experiments each animal was killed by an intravenous injection of barbiturate ( 3 to $4 \mathrm{~g}$ of Sodium Pentobarbital, Vetiquinol SA). Immediately prior to injection of barbiturate a $20 \%\left(\mathrm{v} \mathrm{v}^{-1}\right)$ suspension of Indian Ink in saline was injected into the portal/caval catheter for postmortal evaluation of its intravital position. Postmortem examination included the macroscopic aspect of the carcass (including the surgical sites) and evaluation of the position of the catheters. The presence of ink particles in systemic and portal blood samples was estimated in a semi-quantitative manner after centrifugation of a dilute $(10 \%)$ blood sample after hypotonic hemolysis. Gross aspect and weight of selected organs and histopathology of the liver, kidneys and lungs (fixation: immersion of a thin tissue slice in a fresh $10 \%$ solution of formaldehyde) were examined. Some physiological parameters as observed during the course of the experiment and after termination are presented in Table 1 .

\section{Feed and lysine administration}

Feed was given at a level just exceeding animal maintenance requirements, from the day of surgery onwards. This was aimed to prevent a substantial increase in body 
Table 1. Morphological and physiological characteristics (sex, body weight, organ weights, and rectal temperature) of the experimental animals. $\mathrm{C}=$ cavally catheterized (sham) control; P1, P2 = portally catheterized animals.

\begin{tabular}{lccc}
\hline & $\mathrm{C}$ & $\mathrm{P} 1$ & $\mathrm{P} 2$ \\
Sex $(\mathrm{F}=$ female, $\mathrm{CM}=$ castrated male) & $\mathrm{F}$ & $\mathrm{CM}$ & $\mathrm{CM}$ \\
Body weight at time of surgery $(\mathrm{kg})$ & 45 & 44 & 45 \\
Body weight after euthanasia $(\mathrm{kg})$ & 46 & 49 & 48 \\
Heart $(\mathrm{g})$ & 238 & 268 & 208 \\
Lungs (left + right) $(\mathrm{g})$ & 368 & 414 & 316 \\
Kidneys (both) $(\mathrm{g})$ & 192 & 190 & 170 \\
Liver (g) & 1189 & 1198 & 1082 \\
Rectal temperature at 8:00 h (mean $\pm \mathrm{SD})$ & $38.7 \pm 0.5$ & $38.5 \pm 0.5$ & $38.3 \pm 0.5$ \\
\hline
\end{tabular}

weight during the experimental period and to ensure rapid intake of the daily ration, when this was offered. Protein content of the diet $(16.1 \%)$ was rather low in order not to obscure blood lysine concentrations by high lysine levels derived from the feed. In order to maximize the utilization of dietary amino acids for protein synthesis, dietary amino acid supply was not far in excess of the need for maintenance. Energy content of the diet ( $2150 \mathrm{kcal}$ net energy per $\mathrm{kg}$ feed) was somewhat higher as compared to protein, in order to minimize the oxidation of protein as a source of dietary energy. The composition and results of analysis of the feed are presented in Table 2. The animals were given $48 \mathrm{~g}$ of the experimental feed per $\mathrm{kg}$ metabolic weight $\left(\mathrm{kg}^{0.75}\right)$ at 8:00 h. This amount was saturated with water 20 minutes before feeding. Most of the meal was finished within half an hour. The animals were allowed to drink 41 of water per day, but intake was always less.

Crystalline L-lysine (Fluka Chemie AG) was administered at a daily dose of 0.53 $\mathrm{g} \mathrm{kg}^{-1}$ metabolic body weight $\left(\mathrm{kg}^{0.75}\right)$, corresponding to 62 or $63 \mathrm{mmol}$ per animal weighing 44 or $45 \mathrm{~kg}$, respectively, and was prepared for oral or intravenous administration as follows. The amount needed for four experimental days was weighed and dissolved in distilled water at an initial concentration of $150 \mathrm{~g} \mathrm{l}^{-1}$, yielding a $\mathrm{pH}$ of approximately $10.1 \mathrm{HCl}(5 \mathrm{M})$ was used to adjust $\mathrm{pH}$ to $7.5(0.97 \mathrm{mEq} \mathrm{HCl}$ mmol-1 lysine) and this $\mathrm{pH}$ was found to be maintained when the solution was diluted to the final volume. The concentrated lysine solution was sterilized over a $20 \mu \mathrm{m}$ cellulose acetate sterile filter unit (Nalge Co.). The solution was then divided into four equal portions and each portion was diluted 3 times with sterile distilled water, yielding a slightly hypertonic solution as compared to plasma, and stored at $4{ }^{\circ} \mathrm{C}$ before use (within five days after preparation). The solutions for intravenous administration were brought to $37^{\circ} \mathrm{C}$ immediately before use. Lysine solution for oral administration was added to the water to be mixed with the experimental feed.

L-lysine was administered to each animal in four different ways and then the treatments were repeated once (see Table 3). Within each series the order of the different treatments was randomized (Table 3). The oral dosage (treatment A) was included in the meal, provided at 8:00 h, and intravenous infusions included slow jugular infusion from $9: 00 \mathrm{~h}$ to $10: 00 \mathrm{~h}$ (treatment $\mathrm{B}$ ), rapid jugular infusion from 


\section{J. M. FENTENER VAN VLISSINGEN ET AL.}

Table 2. Composition and amino acid analysis of the experimental feed.

\begin{tabular}{lc}
\hline Composition & \\
\hline Component & Content $\left(\mathrm{g} \mathrm{kg}^{-1}\right)$ \\
& 777 \\
Barley & 194 \\
Tapioca & 15.0 \\
Calcium hydrogen phosphate & 7.0 \\
Calcium carbonate & 2.5 \\
Sodium chloride & 2.0 \\
Vitamin/mineral supplement & 1.5 \\
L-threonine & 1.0 \\
DL-methionine &
\end{tabular}

Amino acid analysis

\begin{tabular}{lcc}
\hline Amino acid & Content $\left(\mathrm{g} \mathrm{kg}^{-1}\right)$ & $\begin{array}{l}\text { Amount predicted to be } \\
\text { digested (mmol kg-1) }\end{array}$ \\
ILE (isoleucine) & & \\
LEU (leucine) & 4.1 & 23 \\
LYS (lysine) & 7.4 & 44 \\
MET (methionine) & 3.5 & 16 \\
CYS (cysteine) & 2.6 & 14 \\
PHE (phenylalanine) & 2.0 & 13 \\
TYR (tyrosine) & 5.4 & 26 \\
THR (threonine) & 3.4 & 14 \\
TRY (tryptophan) & 5.1 & 36 \\
VAL (valine) & 1.5 & 5 \\
ARG (arginine) & 5.6 & 36 \\
HIS (histidine) & 6.2 & 27 \\
ALA (alanine) & 2.5 & 13 \\
ASP (aspartic acid) & 4.5 & 37 \\
GLU (glumatic acid) & 6.6 & 37 \\
GLY (glycine) & 25.5 & 134 \\
PRO (proline) & 4.3 & 42 \\
SER (serine) & 10.7 & 73 \\
\end{tabular}

Table 3. Individual lysine administration schedules for each animal. $\mathrm{A}=$ oral dose $(8: 00 \mathrm{~h})$; $\mathrm{B}=$ jugular infusion $(9: 00 \mathrm{~h}-10: 00 \mathrm{~h}) ; \mathrm{C}=$ jugular bolus injection $(9: 00 \mathrm{~h}) ; \mathrm{D}=$ portal infusion $(9: 00 \mathrm{~h}-$ $10: 00 \mathrm{~h}) ; \mathrm{d}=$ caval infusion $(9: 00 \mathrm{~h}-10: 00 \mathrm{~h})$.

\begin{tabular}{lllllllll}
\hline Animal & \multicolumn{1}{l}{ Rank of experimental day } \\
\cline { 2 - 8 } & 1 & 2 & 3 & 4 & 5 & 6 & 7 & 8 \\
& & & & & & & & \\
C & B & A & d & C & C & d & A & B \\
P1 & B & D & C & A & C & A & B & D \\
P2 & B & C & A & D & C & A & D & B \\
\hline
\end{tabular}


9:00h to $9.10 \mathrm{~h}$ (treatment $C$ ) and slow portal/caval infusion from 9:00 h to 10:00 $\mathrm{h}$ (treatment $\mathrm{D}$ or $\mathrm{d}$, in animals $\mathrm{P} 1$ and $\mathrm{P} 2$, or $\mathrm{C}$, respectively). When lysine was given orally a jugular intravenous dose of $300 \mathrm{ml}$ saline was infused from 9:00 h to 10:00 h. Blood sampling was done at 8:00 h, at 9:00 h, at 9.10 h (treatment C only), every 30 minutes up to $11: 00 \mathrm{~h}$, at $12: 00 \mathrm{~h}$, and at 14:00 h, 16:00 h and 18:00 h. Sample size was $4 \mathrm{ml}$ each time and effectively compensated for by the amount of fluid infused while flushing the catheters.

\section{Amino acid analysis}

Heparinized plasma samples were prepared for amino acid analysis according to Condon (1986) with some slight modifications. For each plasma sample $50 \mathrm{mg}$ of sulfosalicylic acid (J. T. Baker Chemicals) was weighed into a $1.5 \mathrm{ml}$ micro test tube (Eppendorf 3810). Immediately after thawing $1 \mathrm{ml}$ of plasma was pipetted into the tube, mixed thoroughly and kept at $4{ }^{\circ} \mathrm{C}$ for one hour while mixing repeatedly. After centrifuging for 10 minutes at $13100 \mathrm{~g}, 400 \mu \mathrm{l}$ of the supernatant was transferred to a new tube. Adjustment of $\mathrm{pH}$ to approximately 2.2 was done with $50 \mu \mathrm{l}$ of a $1 \mathrm{M}$ solution of $\mathrm{NaOH}$. Norleucine was added as an internal standard to a final concentration of $0.54 \mathrm{mmol} \mathrm{ml}^{-1}$ and the volume was adjusted to $500 \mu \mathrm{l}$ per sample. Amino acid and ammonia concentration was measured by chromatography on a LKB 4151 Alpha Plus amino acid analyzer with the recommended sodium citrate buffer system (Condon, 1986). Injection volume was $40 \mu \mathrm{l}$. When lysine concentration exceeded the specified limit of $0.8 \mathrm{mmol}$ the measurement was repeated with an injection volume of 20 or $10 \mu \mathrm{l}$. Repeated measurements of a large plasma sample, that had been divided into different aliquots prior to freezing, showed the following statistical parameters (mean $\pm \mathrm{SD}, \mathrm{n}=8$ ) for each amino acid (mmol): aspartic acid $0.001 \pm 0.001$; threonine $0.656 \pm 0.107$; serine $0.249 \pm 0.014$; glutamic acid $0.224 \pm 0.009$; proline $0.638 \pm 0.026$; glycine $0.850 \pm 0.015$; alanine 0.889 \pm 0.029 ; cysteine $0.023 \pm 0.008$; valine $0.319 \pm 0.004$; methionine $0.056 \pm 0.001$; isoleucine $0.241 \pm 0.004$; leucine $0.193 \pm 0.004$; tyrosine $0.087 \pm 0.004$; phenylalanine $0.103 \pm 0.009$; histidine $0.052 \pm 0.007$; lysine $0.353 \pm 0.016$; arginine 0.165 \pm 0.006 . The time span of storage of this split sample before and after sample preparation was similar to the storage times of the other samples. Cysteine concentration was reduced by $60 \%$ during the first week of plasma storage and histidine by $26 \%$, while other amino acids appeared to be both stable and quantified in a highly reproducible manner.

To evaluate recovery of lysine from biological matrices, a standard lysine solution was added to equal amounts of whole blood and plasma derived from the same blood sample. The procedure was repeated four times. The samples were allowed to equilibrate for 20 minutes at room temperature prior to processing and storage as described above. The final concentration of the lysine added was $0.200 \mathrm{mmol}$, a concentration similar to the concentration of lysine already present in the samples. Recovery of lysine added to plasma ranged from 91 to $106 \%$ and recovery from whole blood ranged from 108 to $122 \%$. After correction of the blood samples for the cellular component, recovery was found to range from 89 to $99 \%$, indicating 
that during the procedure of equilibration the uptake of lysine by blood cells was less than corresponding to equilibration with plasma. The lysine present in the plasma at the time of sampling was reflecting blood concentrations without appreciable errors.

\section{Data analysis}

Analysis of kinetic parameters of lysine absorption and elimination was done by three different models, dependent on the best mathematical description of the rough data.

Plasma concentration-time curves of lysine after intravenous bolus injection or slow infusion could be described best by a two-compartment model with elimination from the central compartment. The curves obtained after oral administration were adequately described by a one-compartment model with first-order absorption. For standard equations to these models, see Gibaldi \& Perrier (1982). To account for the endogenous lysine levels in plasma, the basal plasma level $\left(C_{B}\right)$ was added to each of the equations used, e.g. $C^{\prime}(t)=C(t)+C_{B}$, where $C^{\prime}(t)$ is the plasma lysine concentration at time $t$, and $C(t)=$ standard equation describing the kinetics of intravenously or orally administered lysine. Plasma levels of each subject were fitted to the appropriate models using the nonlinear least squares regression program NONLIN (Metzler et al., 1974), in which all data were reciprocally weighed $\left(1 / \mathrm{C}^{2}\right)$. From these fits, basic pharmacokinetic parameters were calculated (Gibaldi $\&$ Perrier, 1982). AUC $=$ area under the plasma $C(t)$ curve, TAUC $=$ area under the product of time and $\mathrm{C}(\mathrm{t})$. For intravenous bolus injection (IV) or infusion (INF) the total plasma clearance $\mathrm{CL}=$ dose/AUC, mean residence time $\mathrm{MRT}=$ TAUC/AUC, initial volume of distribution $V_{1}=$ dose $/ C(0)$ where $C(0)$ is the extrapolated zero-time concentration, volume of distribution at steady-state $\mathrm{V}_{\mathrm{SS}}=$ dose $\times$ TAUC/AUC 2 . The bioavailability (F) of lysine as compared to the IV bolus administration was calculated as $\mathrm{AUC}_{\mathrm{INF}} / \mathrm{AUC}_{\mathrm{IV}}$ or $\mathrm{AUC}_{\mathrm{ORAL}} / \mathrm{AUC}_{\mathrm{IV}}$. In case of oral administration $\mathrm{CL}=\mathrm{F} \times$ dose $/ \mathrm{AUC}$ and $\mathrm{V}_{\mathrm{SS}}=\mathrm{F} \times$ dose $/ \mathrm{AUC} \times \mathrm{k}_{\mathrm{el}}$, where $\mathrm{k}_{\mathrm{el}}$ $=$ rate constant of elimination. The mean absorption time $\mathrm{MAT}=\mathrm{MRT}_{\text {ORAL }}-$ $\mathrm{MRT}_{\mathrm{IV}}$. Half-lives of the terminal exponential phase $\left(\mathrm{t}_{1 / 22}\right)$ and absorption phase $\left(t_{1 / 2 a}\right)$ were obtained from their respective rate constants.

Basal and peak plasma concentrations of all amino acids analysed and ammonia, were derived from the rough data as follows. Only data derived from experimental days, when the experimental dose of lysine was administered orally, were included. A postprandial peak was identified if a distinct postprandial maximum occurred. If this maximum presented itself as a plateau, the times of reaching the maximum and the beginning of the decline thereafter were averaged. The difference between basal and peak concentrations were calculated for each experimental day, from the rough data, and then averaged. A second maximum was identified if this second maximum was of similar amplitude as the first, on the same day, and if it followed a distinct transitional decline after the first peak. 


\section{Results}

Recovery from surgery by the animals and subsequent experiments were uncomplicated. The animals were never feverish and somatic growth (increase of body weight, as assessed after an overnight fast) during the experimental period ranged

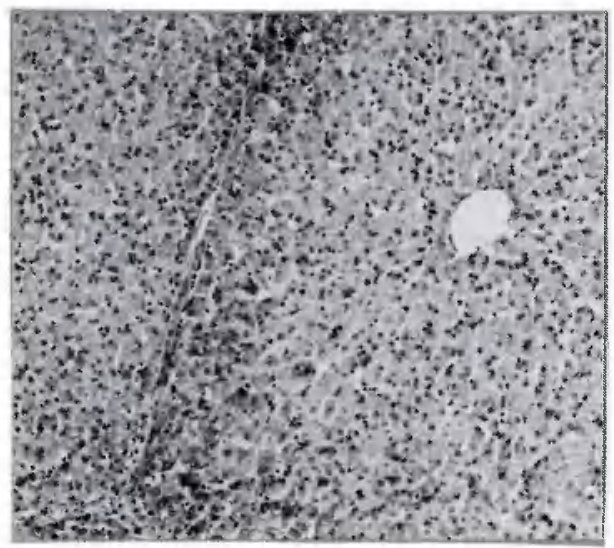

1A

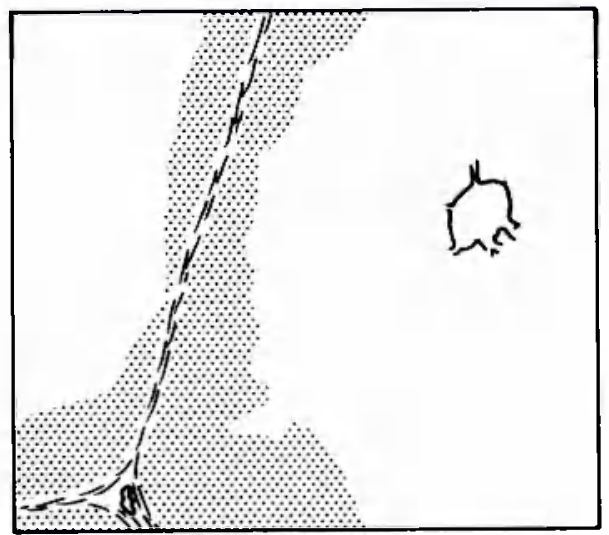

IB

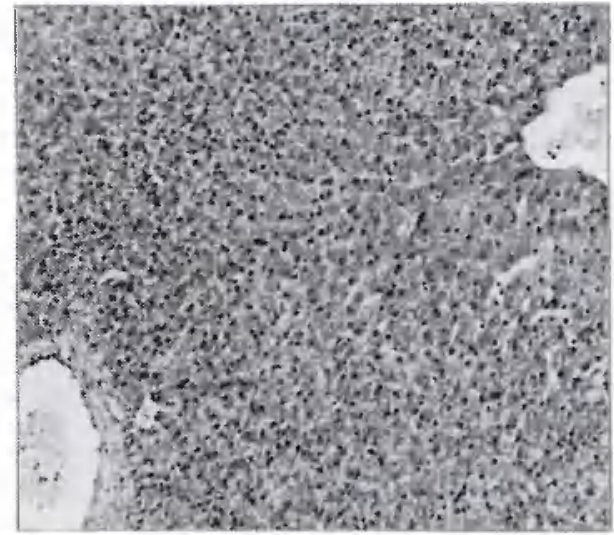

$2 \mathrm{~A}$

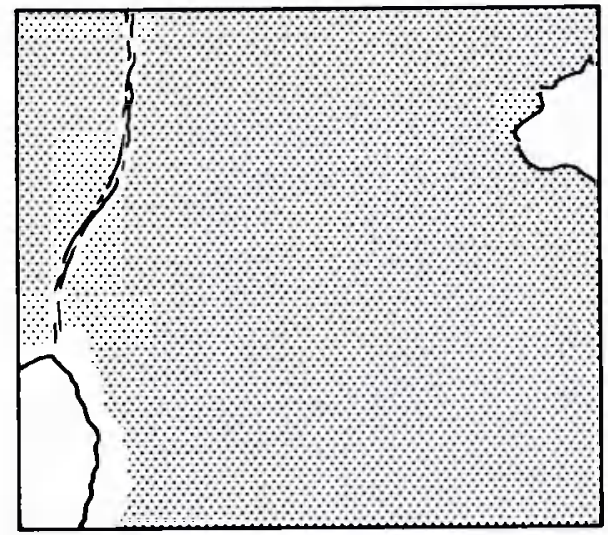

2B

Fig. 2. Histology of the liver of animals $C$ (caval infusion, panels $1 A$ and IB) and PI (portal infusion, panels $2 \mathrm{~A}$ and $2 \mathrm{~B}$ ). The microphotographs in panels $1 \mathrm{~A}$ and $2 \mathrm{~A}$ are represented schematically in panels $1 \mathrm{~B}$ and $2 \mathrm{~B}$, respectively. Periodic-Schiff-staining revealed glycogen (dark staining in panels $1 \mathrm{~A}$ and $2 \mathrm{~A}$, shaded areas in panels IB and 2B). Glycogen was demonstrated in the hepatic parenchymal cells in zone I (periportal) of the hepatic acinar unit (Rappaport et al., 1954; Rappaport \& Hiraki, 1958) in the cavally infused animal (panel $1 \mathrm{~A}$ and $\mathrm{B}$ ). In the portally infused animals (panels $2 \mathrm{~A}$ and $2 \mathrm{~B}$ ) glycogen storage ocurred in the cells in zones I, II and III of the acinar units. Rappaport et al. (1954) defined the hepatic acinar unit as the functional unit of the liver and numbered the successive zones I (periportal) to III (surrounding the central vein). Enlargement of the liver cells caused partial occlusion of the liver sinusoids. Magnification $=83 \times$. 
from 1 to $4 \mathrm{~kg}$ (Table 1) and corresponded to the restricted feeding regimen. Gross aspect and weight of organs provided no indication of functional disturbances. Catheter position as evaluated by dissection and recovery of ink particles indicated that two animals (P1 and P2) had the catheter in the portal venous system with the tip at the junction with the cranial mesenteric vein, and one animal (C) had the catheter in caval position. This control animal proved valuable with respect to the causal explanation of hepatic changes, as detected in animals P1 and P2, but not in $\mathrm{C}$ (see Figure 2). These changes of the liver were characterized by cellular swelling, caused by extensive glycogen storage in zones I, II and III of the liver parenchyma (Rappaport et al., 1954; Rappaport \& Hiraki, 1958), and causing partial occlusion of the liver sinusoids.

Elimination kinetics after rapid intravenous (jugular) infusion of lysine were best described by a two-compartment model. The deduced kinetic parameters are presented in Table 4 and an example of plasma lysine concentration as a function of time, and fitted curve, is shown in Figure 3A. The area under the curve (AUC) ranged from 5.04 to $7.21 \mathrm{mmol} \mathrm{h}^{-1} \mathrm{l}^{-1}$. Mean residence time (MRT) ranged from 1.0 to $4.8 \mathrm{~h}$, plasma clearance $(\mathrm{CL})$ was 0.19 to $0.28 \mathrm{l} \mathrm{h}^{-1} \mathrm{~kg}^{-1}$, and elimination half-life $\left(t_{1 / 2 z}\right)$ was 0.1 to $5.3 \mathrm{~h}$. These data indicate that lysine is eliminated quite rapidly from the plasma under these circumstances. Volume of distribution of the central compartment $\left(\mathrm{V}_{1}\right)$ was 0.17 to $0.221 \mathrm{~kg}^{-1}$ and volume of distribution at steady state $\left(\mathrm{V}_{\mathrm{SS}}\right)$ was 0.28 to $0.931 \mathrm{~kg}^{-1}$. Thus, after an initial rapid distribution over the plasma (blood) compartment there is some expansion to a second, larger compartment, including other extracellular and intracellular fluid compartments.

Kinetics of plasma lysine concentration after slow intravenous (jugular, caval, or portal) infusion were also analysed by a two-compartment model, but infusion and elimination kinetics were calculated separately. The kinetic parameters after central venous infusion are presented in Table 4 and a typical example of plasma concentration as a function of time, and fitted curve, is presented in Figure 3B. The data ob-

Table 4. Pharmacokinetic parameters of lysine after intravenous (jugular) bolus injection, intravenous infusion (jugular or caval), and oral administration (mean $\pm \mathrm{SD}$ ).

\begin{tabular}{|c|c|c|c|}
\hline & $\begin{array}{l}\text { Intravenous } \\
\text { bolus } \\
(\mathrm{n}=6)\end{array}$ & $\begin{array}{l}\text { Intravenous } \\
\text { infusion } \\
(\mathrm{n}=8)\end{array}$ & $\begin{array}{l}\text { Oral } \\
\text { administra- } \\
\text { tion } \\
(\mathrm{n}=6)\end{array}$ \\
\hline Bioavailability & 1.00 & $0.91 \pm 0.16$ & $0.82 \pm 0.06$ \\
\hline Clearance $\left(\mathrm{h}^{-1} \mathrm{~kg}^{-1}\right)$ & $0.24 \pm 0.03$ & $0.25 \pm 0.04$ & $0.24 \pm 0.04$ \\
\hline Initial volume of distribution $\left(\mathrm{kg}^{-1}\right)$ & $0.18 \pm 0.02$ & $0.26 \pm 0.03$ & - \\
\hline Volume of distribution at steady-state $\left(1 \mathrm{~kg}^{-1}\right)$ & $0.43 \pm 0.25$ & $0.62 \pm 0.22$ & $0.29 \pm 0.10$ \\
\hline Mean residence time $(\mathrm{h})$ & $1.9 \pm 1.4$ & $2.6 \pm 1.2$ & $6.5 \pm 1.4$ \\
\hline Mean absorption time (h) & - & - & $4.5 \pm 1.8$ \\
\hline Half-life of the terminal exponential phase (h) & $2.0 \pm 1.6$ & $3.7 \pm 1.9$ & $0.9 \pm 0.3$ \\
\hline Half-life of the absorption phase (h) & - & - & $3.6 \pm 0.9$ \\
\hline Basal lysine concentration (mmol $1-1)$ & $0.24 \pm 0.02$ & $0.23 \pm 0.03$ & $0.22 \pm 0.03$ \\
\hline
\end{tabular}


tained after portal infusions were similar to those found after jugular or caval infusion. A typical example of plasma lysine concentration after portal infusion, and fitted curve, is shown in Figure $3 \mathrm{C}$. The area under the curve (AUC) ranged from 4.24 to $6.54 \mathrm{mmol} \mathrm{h}^{-1 \mathrm{l}^{-1}}$ after infusion into a systemic vein and from 3.85 to 5.29 mmol $h^{-1} l^{-1}$ after portal infusion, indicating that no detectable liver first-pass effects were present. The range of AUC after slow intravenous infusion overlaps the
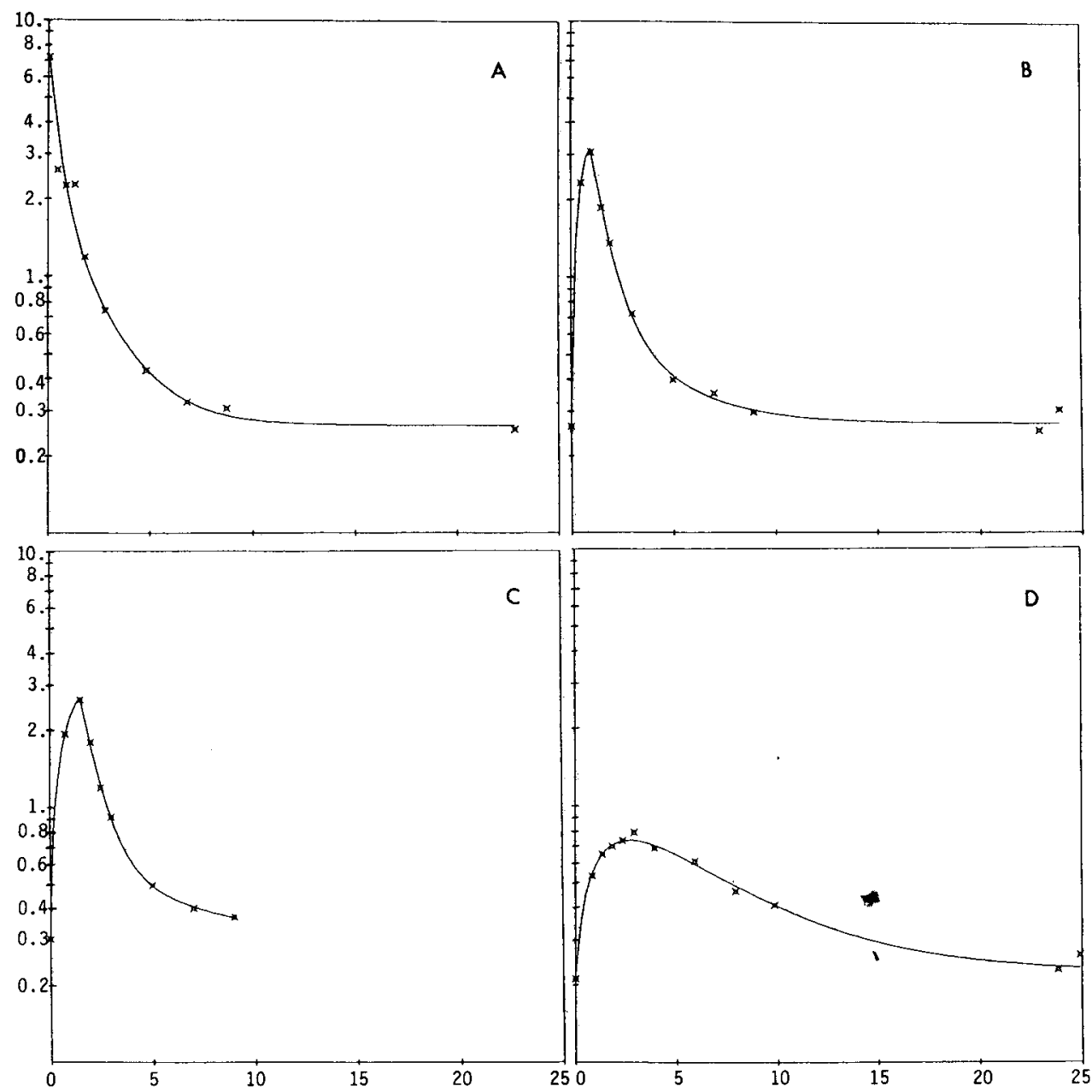

Fig. 3. Plasma lysine concentration (Y-axis, logarithmic, mmol $1^{-1}$ ) in relationship to time (X-axis, linear, hours) after administration of $0.53 \mathrm{~g} \mathrm{~kg}-0.75$ via different routes and at different rates. Typical examples of each treatment (animal P1) are shown, presenting both the rough data and the curves fitted according to the models referred in the 'Materials and Methods' section. Refer to Table 4 for pharmacokinetic parameters. (A) jugular bolus injection, (B) jugular infusion, (C) portal infusion, (D) oral administration. 
range found after jugular bolus injection. Mean residence time (MRT) and clearance (CL) after slow intravenous infusion are similar to these parameters after jugular bolus injection aswell. Elimination half-life after slow intravenous infusion is greater than this parameter following jugular bolus injection, indicating other elimination kinetics being involved after the two different administration patterns. Distribution volume in the central compartment tends to be somewhat larger after slow intravenous infusion $\left(0.22\right.$ to $\left.0.331 \mathrm{~kg}^{-1}\right)$ than after jugular bolus injection, indicating progression to steady state distribution during the infusion period.

The kinetics of plasma lysine concentration after oral administration are presented in Table 4 and Figure 3D. After oral administration of lysine the concentration in the systemic blood increased with a time constant $\left(\tau_{\mathrm{abs}}\right)$ of 3.8 to $7.6 \mathrm{~h}$ and an absorption half-life of 2.6 to $5.3 \mathrm{~h}$ (Table 4), indicating that absorption from the intestine takes several hours and is dependent on absorption kinetics rather than enzymatic digestion, which clearly is not an essential step in the digestion of lysine monomers. The oral uptake of lysine derived from the basal ration is negligible as compared to the experimental oral dose and was present during comparative in-

Table 5. Basal plasma concentration $\left(\mu \mathrm{mol} 1^{-1}\right)$, postprandial peak concentration $\left(\mu\right.$ mol $\left.1^{-1}\right)$, difference between basal and first-peak concentration (diff; $\mu$ mol l-1), time after meal of peak incidence (h), amplitude of the second peak (ampl, $\mu \mathrm{mol} \mathrm{l}^{-1} ;(\mathrm{n})=$ incidence rate of a second peak), of all amino acids analysed, and ammonia. $\mathrm{SD}=$ standard deviation about the mean; $n=6$.

\begin{tabular}{|c|c|c|c|c|c|c|c|c|c|c|c|}
\hline & \multicolumn{8}{|c|}{ First peak } & \multicolumn{3}{|c|}{ Second peak } \\
\hline & \multicolumn{2}{|l|}{ basal } & \multicolumn{2}{|l|}{ peak } & \multicolumn{2}{|l|}{$\operatorname{diff}$} & \multicolumn{2}{|l|}{ time } & \multicolumn{2}{|l|}{ ampl } & \multirow{2}{*}{$\begin{array}{l}\text { time } \\
\text { range }\end{array}$} \\
\hline & mean & SD & mean & $\mathrm{SD}$ & mean & $\mathrm{SD}$ & mean & range & mean & (n) & \\
\hline ASP & 11 & 9 & 13 & 10 & 2 & 3 & 2.3 & $2.0-2.8$ & 22 & (1) & 4 \\
\hline GLU & 265 & 41 & 365 & 47 & 100 & 20 & 1.9 & $1.5-2.5$ & 385 & (1) & 10 \\
\hline ALA $^{1}$ & 451 & 142 & 771 & 83 & 321 & 79 & 1.9 & $1.5-2.5$ & 805 & (1) & 10 \\
\hline CYS & 17 & 9 & 30 & 10 & 14 & 4 & 2.5 & $1.5-4.0$ & 35 & (5) & $8-10$ \\
\hline GLY & 762 & 73 & 799 & 100 & 37 & 44 & 1.4 & $1.0-3.0$ & 778 & (2) & 10 \\
\hline ILE & 130 & 27 & 170 & 34 & 40 & 15 & 1.5 & $1.0-2.0$ & & & \\
\hline LEU & 83 & 14 & 137 & 28 & 53 & 22 & 1.4 & $1.0-2.0$ & 107 & (1) & 8 \\
\hline MET & 21 & 5 & 66 & 14 & 45 & 11 & 2.1 & $1.5-2.5$ & 56 & (1) & $4-6$ \\
\hline PHE & 54 & 14 & 100 & 6 & 46 & 17 & 2.3 & $1.5-3.0$ & 106 & (4) & $3-8$ \\
\hline SER & 153 & 20 & 193 & 34 & 40 & 17 & 1.8 & $1.0-2.5$ & 181 & (2) & $8-10$ \\
\hline $\mathrm{THR}^{2}$ & 509 & 116 & 728 & 126 & 219 & 55 & 1.9 & $1.0-2.5$ & & & \\
\hline TYR & 38 & 9 & 71 & 9 & 33 & 17 & 1.9 & $1.5-2.5$ & 70 & (3) & $8-10$ \\
\hline VAL & 207 & 22 & 291 & 41 & 84 & 25 & 2.0 & $1.5-3.0$ & 286 & (2) & $8-10$ \\
\hline ARG & 106 & 19 & 184 & 47 & 78 & 31 & 1.8 & $1.0-3.0$ & 307 & (3) & $4-10$ \\
\hline HIS & 45 & 12 & 64 & 15 & 20 & 7 & 2.1 & $1.5-2.5$ & & & \\
\hline LYS 3 & 212 & 29 & 863 & 74 & 651 & 95 & 2.1 & $1.5-3.0$ & 873 & (1) & 4 \\
\hline PRO & 233 & 43 & 492 & 54 & 259 & 49 & 2.3 & $2.0-3.0$ & 577 & (1) & 3 \\
\hline AMM & 239 & 110 & 340 & 158 & 101 & 115 & 2.7 & $1.5-4.0$ & 307 & (3) & $4-10$ \\
\hline
\end{tabular}

1 Refer also to Figure 4 for accumulating pattern of ALA.

2,3 THR and LYS were supplemented to the feed as free amino acids. 
travenous dosage schedules and therefore treated as an endogenous level in data analysis. Elimination kinetics of lysine after an oral dose were best described by a time constant $\left(\tau_{\mathrm{cl}}\right)$ of 0.4 to $1.5 \mathrm{~h}$ and an elimination half-life of 0.4 to $1.1 \mathrm{~h}$, and thus similar to elimination kinetics after jugular infusion (Table 4). Concentration at steady state $\left(\mathrm{C}_{\mathrm{B}}\right)$ ranged from 0.10 to $0.26 \mathrm{mmol} \mathrm{l}^{-1}$. The area under the curve (AUC) after oral administration ranged from 3.90 to $6.34 \mathrm{mmol} \mathrm{h}^{-1} \mathrm{I}^{-1}$. Mean residence time (MRT) after oral administration ranged from 4.1 to $8.5 \mathrm{~h}$.

Bioavailability of lysine after an oral dose was deduced from kinetic parameters shown in Table 4. The mean area under the curve after oral administration in each animal was divided by the mean area under the curve after intravenous bolus injection in the same animal and expressed as the fraction absorbed. The oral bioavailability was $82 \pm 6 \%$ (Table 4).

The postprandial pattern of plasma concentrations of amino acids other than lysine (Table 5) was not identical for each amino acid analysed. Amino acids showing a distinct postprandial maximum were GLU, ALA, LEU, MET, PHE, THR, TYR, VAL, ARG, HIS, LYS and PRO, while only a minor postprandial rise was observed with respect to ASP, CYS, GLY, ILE and SER. The time after a meal when maximum concentration occurred was, generally, 1 to $3 \mathrm{~h}$ for all amino acids, including lysine (refer also to Figure 3D). A second rise of plasma concentration, occurring later during the day, was observed for many amino acids, although not on every experimental day. Plasma ammonia concentration rose postprandially, but to a very variable extent.

Plasma alanine, and in one animal also plasma glycine, tended to accumulate during the experimental period (Figure 4). This may indicate excessive production of alanine, but also indicates a rather limited clearance rate.

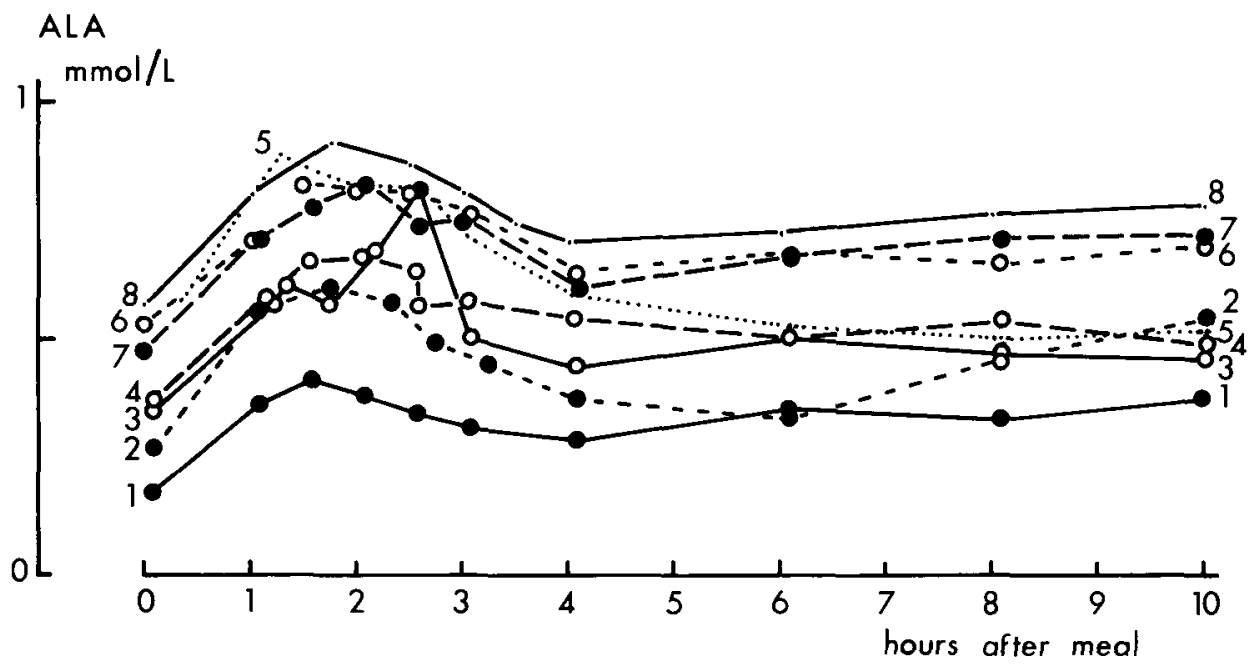

Fig. 4. Plasma alanine concentration at each day of the experiment, showing gradual increase in alanine concentration during the experiment. The figure accompanying each curve is the rank number of each day of the experiment. 


\section{Discussion}

The present experiment was designed to explore the potential of a pharmacokinetic approach to determine amino acid absorption and metabolism (bioavailability) by analysis of changes in plasma concentrations.

The approach used to catheterize the portal venous system ensured introduction of the infusate at a site very near the junction of jejunal portal effluent. This may be significant with respect to putative directional flow from specified portal drained viscera to some areas of the liver. The accuracy of the technique, however, can only be verified afterwards, when the animal is sacrificed. Therefore, this catheterization technique may not be the method of choice for large-scale experiments.

The hepatic changes observed in those animals that had been infused with lysine through the portal vein, contrasting with the control animal that had been infused intracavally, remain unexplained. No direct hepatotoxic effects from lysine have been documented so far, and ionic strength and $\mathrm{pH}$ of the solution were not likely to cause any tissue damage when infused at a rate so slow. The intravenous load of lysine per se did not cause any excessive hepatic glycogen storage in the control animal, so hepatic changes were apparently associated with the portal route of introduction and may depend on a regional endo-/paracrine mechanism. The excessively high peak concentrations of lysine had no apparent negative effect on animal health or behaviour. The distribution of lysine over blood plasma and cellular compartments, in vivo and in vitro, indicated that lysine initially occupied the extracellular fluid compartment. Later, amino acids including lysine can be enriched in tissues and blood cells as compared to plasma (Edmonds \& Baker, 1987; van Berlo, 1988).

The quantification of enteral uptake of lysine by plasma kinetic parameters seems to be suitable when various routes of administration are compared. The enteral absorption kinetics show that uptake occurred at a substantial rate during several hours after intake, starting quite rapidly. Half of the lysine was absorbed after approximately three to five hours. Enzymatic hydrolysis of protein, often thought to be the rate limiting step in protein digestion, did not play a role in this model and it is thus concluded that enteral absorption was the rate limiting step in the process of transfer of lysine to the systemic pool. This corresponds to the observations of Buraczewski et al., (1980), who measured the rate of disappearance from the digesta directly. Their observation, that lysine is absorbed slowly as compared to other amino acids, may be supported by this study.

Plasma concentrations of both lysine and threonine (that was included in the feed as a synthetic monomer as well) reached postprandial maxima during the same time span as other amino acids, that had to be liberated by hydrolysis prior to absorption. Enteral absorption of amino acids is a carrier-dependent process and basic amino acids compete for the same receptor (Rook, 1983). The rate of absorption corresponded well to portal absorption data obtained by Rerat (1985). Also, peptide degradation products from enzymatic hydrolysis of proteins in the digestive tract may be absorbed readily (Kushak \& Basova, 1988) and are then rapidly degraded after appearance in systemic circulation (Stehle et al., 1988). The second postprandial maximum of plasma amino acids, as this was observed frequently, may be related 
to the digestion and reabsorption of amino acids, that were incorporated in digestion-related secretory proteins or cellular proteins from the gastro-intestinal mucosa. It may also reflect protein degradation products from other tissues as protein is mobilized to maintain plasma levels during intervals between meals. The amino acid pattern does, however, not correspond to the profiles after extended fasting as reported by Edmonds \& Baker (1987).

Elimination of plasma lysine occurred at a similar rate after each route of administration. This does not proof, but suggest, that elimination mechanisms involved may be identical in each case. This is surprising when the great differences in amplitude and time of the maximum after different routes of administration are considered. Apparently, elimination rate was not enhanced when plasma concentrations of lysine were excessive. Elimination of lysine from plasma may occur in different ways, for example conversion to other amino acids by reduction of the part of the molecule that is specific to lysine, by desamination and/or decarboxylation, by oxidation (Imura \& Walser, 1988; Reiser et al., 1988; Jahoor et al., 1988), by excretion or by incorporation into peptides/proteins. The incorporation of labelled lysine administered orally or intravenously in human milk proteins was somewhat faster after intravenous bolus injection, but cumulative incorporation after several hours was identical (Irving et al., 1988). Urinary excretion may be a function of plasma concentration (Tsuchiya et al., 1989).

Hepatic metabolism seemed to be quantitatively insignificant, while no liver firstpass effect was detected by the methods used. The bioavailability of an oral dose of lysine was high, indicating that enteral metabolism is limited. The elimination pattern reported in this study applies to the specific experimental conditions (growing animals maintained on a low-protein maintenance ration). It may not be extrapolated to different experimental situations without extended experiments. The fate of lysine that was not recovered in the systemic blood may be either metabolism by enteral microflora or intestinal tissues, or luminal transfer through the gut. The latter option was not quantified, but generally free amino acids added to the feed have disappeared by $100 \%$ from the digesta when these arrive at the end of the small intestine (Sauer \& Ozimek, 1986). In cecectomized fowl, bioavailability of synthetic lysine is $100 \%$, as quantified by a highly sensitive comparative growth trial comparing intraperitoneal (IP) and oral administration (Izquierdo et al., 1988). However, enteral and IP administration will both result in portal uptake. Furthermore, lysine metabolism by intestinal tissues and microflora may be subject to interspecies differences.

Although amino acids may not be stored by the animal as effectively as fat or glucose, the slow characteristics of absorption and elimination kinetics account for a circulating pool that well covers the usual between-meals intervals. During extended intervals between meals ( 24 hours in this study) tissue proteins are degraded to provide adequate levels of circulating amino acids. The glucogenic amino acid alanine may be liberated in excess (Edmonds \& Baker, 1987), presumably as a substrate for gluconeogenesis. Alanine accumulated from day to day in all three animals studied. Alanine may represent an enteric metabolite of various amino acids, or may derive from tissue (muscle) proteins that were degraded during the postabsorptive period. 
The limited elimination rate of this alanine is not easily interpreted. Alanine can effectively serve as a substrate for gluconeogenesis (Diamond et al., 1988; Edmonds \& Baker, 1987; Istfan et al., 1988; Kimura et al., 1987; Wasserman et al., 1988). Although the capacity of the liver to eliminate alanine is limited (Vilstrup \& Skovgaard, 1988), the accumulation observed was not anticipated. Furthermore, no direct relationship to the hepatic changes of the liver after portal infusion can be discerned, because the alanine accumulation occurred in the cavally catheterized control animal as well.

The approach of quantification of bioavailability of nutritional amino acids by studying plasma kinetics may be a useful tool in the prediction of nutritional value of feeds and feedstuffs, when the limitations of the method are respected. Firstly, it was shown that not all amino acids show a distinct postprandial peak. It seems that only the uptake of amino acids with distinct changes in postprandial plasma concentrations can be evaluated this way. Secondly, although this experiment on lysine did not reveal a hepatic first-pass effect, this does not predict such an effect to be absent with respect to other amino acids to be studied (Rerat, 1985).

Another consideration, that may apply to other amino acids, concerns putative strong physiological or pathological effects to occur when plasma concentrations are excessive. The research on functional plasma amino acid levels may also lead to the definition of desirable (recommended) plasma amino acid patterns in relationship to growth. This would provide a method to evaluate feeds, but also feeding strategies, with respect to bioavailability of dietary protein for animal production. It is, however, a field that has hardly been explored yet and that only comes within view by the introduction of more efficient methods of quantification of amino acids. If one is interested in mechanisms rather than quantification of the metabolism of amino acids, the use of radioactive or stable isotopically labelled compounds seems inevitable, and organ metabolism might be better studied in vitro than in vivo. There is a wealth of data on amino acid metabolism in rats, but it seems not justified to apply this knowledge to pigs without further confirmation of the nature and amplitude of each mechanism as it occurs in the target animal.

\section{Acknowledgements}

Thanks are due to H. Everts and A. M. van Vuuren for surgical assistance, to J. Th. M. van Diepen for preparing the experimental feed, to T. Koorn and R. Terluin and staff for animal care and to S. Klaver and Mrs A. J. Steinmeijer for amino acid analyses.

\section{References}

Berlo, C. L. H. van, 1988. Splanchnic amino acid and ammonia metabolism - studies in the pig. Doctoral Thesis, University of Maastricht, Netherlands, 99 pp.

Buraczewski, S., 1980. Aspects of protein digestion and metabolism in monogastric animals. In: H. J. Oslage \& K. Rohr (Eds.). Proceedings of the Third Symposium of the European Association of Animal Science, Vol. 1, p. 179-195. Bundesforschungsanstalt für Landwirtschaft FAL, Braunschweig, BRD. 
Buttery, P. J. \& D. B. Lindsay (Eds.), 1980. Protein deposition in animals. Butterworths, London, Boston, $305 \mathrm{pp}$.

Condon, G. D., 1986. Amino acid analysis - Theory and laboratory techniques. LKB Biochrom Ltd., Cambridge, UK, $62 \mathrm{pp}$.

Diamond, M. P., R. C. Rollings, K. E. Steiner, P. E. Williams, W. W. Lacy \& A. D. Cherrington, 1988. Effect of alanine concentration independent of changes in insulin and glucagon on alanine and glucose homeostasis in the conscious dog. Metabolism 37:28-33.

Edmonds, M. S. \& D. H. Baker, 1987. Effects of fasting on tissue amino acid concentrations and ureacycle enzymatic activities in young pigs. Journal of Animal Science 65:1538-1552.

Gibaldi, M. \& D. Perrier, 1982. Pharmacokinetics. Marcel Dekker Inc., New York, 494 pp.

Imura, K. \& M. Walser, 1988. Rate of whole body protein synthesis in the rat as calculated from fractional oxidation of leucine, valine, or methionine. Metabolism 37: 591-596.

Irving C. S., E. W. Malphus, M. R. Thomas, L. Marks \& P. D. Klein, 1988. Infused and ingested labeled lysines: appearance in human-milk proteins. American Journal of Clinical Nutrition 47:49-52.

Istfan, N. W., P. R. Ling, B. R. Bistrian \& G. W. Blackburn, 1988. Systemic exchangeability of enteral leucine: relationships to plasma flux. American Journal of Physiology 254:R688-R698.

Izquierdo, O. A., C. M. Parsons \& D. H. Baker, 1988. Bioavailability of lysine in L-lysine-HSl. Journal of Animal Science 66:2590-2597.

Jahoor, F., A. A. Jackson \& M. H. N. Golden, 1988. In vivo metabolism of nitrogen precursors for urea synthesis in the postprandial rat. Annals of Nutrition and Metabolism 32:240-244.

Kimura, R. E., T. R. LaPine, J. Johnston \& J. Z. Ilich, 1987. The effect of fasting on rat portal venous and aortic blood glucose, lactate, alanine, and glutamine. Pediatric Research 23:241-244.

Kushak, R. \& N. Basova, 1988. The absorption of free and 'peptide' amino acids in the small intestine of chicks. Comparative Biochemistry and Physiology 89A:317-322.

Metzler, C. M., G. K. Elfring \& A. J. McEwen, 1974. A package of computer programs for pharmacokinetic modeling. Biometrics 30:562-563.

Rappaport, A. M., Z. J. Borowy, W. M. Lougheed \& W. N. Lotto, 1954. Subdivision of hexagonal liver lobules into a structural and functional unit. Role in hepatic physiology and pathology. The Anatomical Record 119:11-33.

Rappaport, A. M. \& G. Y. Hiraki, 1985. The anatomical pattern of lesions in the liver. Acta Anatomica 32:126-140.

Reiser, W., J. Vogt \& J. R. Reichl, 1988. Growth model for the pig on the basis of amino acid compostion of the diet. Journal of Animal Physiology and Animal Nutrition 60:96-101.

Rerat, A. A., 1985. Intestinal absorption of end products from digestion of carbohydrates and proteins in the pig. Archives of Animal Nutrition 35:461-480.

Rook, J. A. F., 1983. Nutritional imbalances. In: J. A. F. Rook, P. C. Thomas (Eds), Nutritional physiology of farm animals, p. 369-414. Longman Group Lid, NY.

Sauer, W. C. \& L. Ozimek, 1986. Digestibility of amino acids in swine: results and their practical applications. A review. Livestock Production Science 15:367-388.

Stehle, P., S. Albers, L. Pollack \& P. Fürst, 1988. In vivo utilization of systine-containing synthetic short-chain peptides after intravenous bolus injection in the rat. Journal of Nutrition 118:1470-1474.

Tsuchiya, H. T. Hayashi, M. Tatsumi, Y. Hoshino, S. Ohtani \& N. Takagi, 1989. High-performance liquid-chromatographic analysis for serotonin and tryptamine excreted in urine after oral loading with L-tryptophan. Clinical Chemistry 35:43-47.

Vilstrup, H. \& L. T. Skovgaard, 1988. Kinetics of hepatic alanine uptake and urea synthesis in pigs. American Journal of Physiology 254:G602-G609. 